\title{
HIV-1 Tat activates indoleamine 2,3 dioxygenase in murine organotypic hippocampal slice cultures in a p38 mitogen-activated protein kinase- dependent manner
}

\author{
Xin Fu', Marcus A Lawson ${ }^{1,3}$, Keith W Kelley ${ }^{1,2,3}$ and Robert Dantzer ${ }^{1,2,3^{*}}$
}

\begin{abstract}
Background: We have established that activation of the tryptophan degrading enzyme indoleamine 2,3 dioxygenase (IDO) mediates the switch from cytokine-induced sickness behavior to depressive-like behavior. Because human immunodeficiency virus type 1 (HIV-1) Tat protein causes depressive-like behavior in mice, we investigated its ability to activate IDO in organotypic hippocampal slice cultures (OHSCs) derived from neonatal C57BL/6 mice.
\end{abstract}

Methods: Depressive-like behavior in C57BL/6J mice was assessed by the forced swim test. Expression of cytokines and IDO mRNA in OHSCs was measured by real-time RT-PCR and cytokine protein was measured by enzyme-linked immunosorbent assays (ELISAs). p38 MAPK phosphorylation was analyzed by western blot.

Results: Intracerebroventricular (i.c.v.) administration of Tat (40 ng) induced depressive-like behavior in the absence of sickness. Addition of Tat ( $40 \mathrm{ng} / \mathrm{slice}$ ) to the medium of OHSCs induced IDO steady-state mRNA that peaked at $6 \mathrm{~h}$. This effect was potentiated by pretreatment with IFN $\gamma$. Tat also induced the synthesis and release of TNF $\alpha$ and IL-6 protein in the supernatant of the slices and increased expression of the inducible isoform of nitric oxide synthase (iNOS) and the serotonin transporter (SERT). Tat had no effect on endogenous synthesis of IFN $\gamma$. To explore the mechanisms of Tat-induced IDO expression, slices were pretreated with the p38 mitogen-activated protein kinase (MAPK) inhibitor SB 202190 for 30 min before Tat treatment. SB 202190 significantly decreased IDO expression induced by Tat, and this effect was accompanied by a reduction of Tat-induced expression of TNF $\alpha$, IL6, iNOS and SERT.

Conclusion: These data establish that Tat induces IDO expression via an IFNy-independent mechanism that depends upon activation of p38 MAPK. Targeting IDO itself or the p38 MAPK signaling pathway could provide a novel therapy for comorbid depressive disorders in HIV-1-infected patients.

\section{Background}

The risk of major depressive disorder (MDD) in human immunodeficiency virus (HIV)-infected patients is significantly greater than that in the general population $[1,2]$. Although highly active antiretroviral therapy (HAART) appears to suppress viral replication, there is a high level of microglial activation in the central nervous

\footnotetext{
* Correspondence: dantzer@illinois.edu

'Integrative Immunology and Behavior Program, Department of Animal Sciences, College of ACES, University of Illinois at Urbana-Champaign, Urbana, Illinois 61801, USA

Full list of author information is available at the end of the article
}

system (CNS) of the post HAART-treated patients [3], indicating that eliminating virus may not stop the process of HIV-induced ongoing inflammation in the brain. It has long been known that virus infected monocytes are able to invade the brain and induce a local inflammatory chain reaction that involves the synthesis and release of proinflammatory cytokines by infected and non-infected macrophages and microglia. In addition, infected cells can shed viral proteins such as gp120 and Tat which can activate glial cells by themselves and therefore contribute to the propagation of inflammation 
[4,5]. Although the production of inflammatory mediators by glial cells exposed to HIV-1 proteins has been mainly studied in the context of AIDS-related dementia $[6,7]$, there is still limited evidence that HIV-1 proteins administered into the brain can induce depressive-like behavior in preclinical models with laboratory rodents. Rats injected with gp120 into the lateral ventricle of the brain present with signs of sickness associated with increased production of proinflammatory cytokines. Some of these behavioral alterations, such as the decreased preference for a saccharin solution, mimic the anhedonia observed in depressed patients [8,9]. Intracerebral administration of HIV-1 Tat to mice induces depressive-like behavior in mice as measured by increased immobility in the forced swim and tail suspension tests, together with increased expression of brain proinflammatory cytokines [10].

We have already established that development of inflammation-associated depression is dependent on activation of the tryptophan degrading enzyme indoleamine 2,3 dioxygenase (IDO) by proinflammatory cytokines such as IFN $\gamma$ and TNF $\alpha[11,12]$. IDO degrades tryptophan (Trp) into kynurenine (KYN) which can be further metabolized into neurotoxic metabolites such as 3-hydroxykynurenine and quinolinic acid (QUIN) [13]. In addition to developing depressive-like behaviors, Tattreated mice also display increased IDO expression in their brains [10]. The occurrence of neuropsychiatric disorders in HIV-1 seropositive patients presenting with symptoms of neuro-AIDS is associated with activation of IDO in peripheral macrophages, as evidenced by decreased levels of circulating Trp and increased plasma levels of both KYN and the macrophage activation marker neopterin [14]. Confirmation that IDO activation also takes place in the brain of HIV-infected patients has been obtained since IDO enzymatic activity is increased in the brain of HIV-infected patients with HIV-associated dementia (HAD) [15]. IDO expression is up-regulated in monocytic cells in brain tissue of both patients with HIV-1 encephalitis (HIVE) [16] and monkeys infected with simian immunodeficiency virus encephalitis (SIVE) [17]. Furthermore increases in brain QUIN are associated with progression of HIV infection [18]. Brain expression of IDO during HIV infection certainly contributes to immunotolerance since administration of the IDO competitive inhibitor 1-methyl tryptophan enhances elimination of virus-infected macrophages in mice with HIVE [16].

There is evidence that HIV-1 Tat can induce IDO expression in various cell types. This is particularly the case in macrophages $[19,20]$ but also in astrocytes exposed to HIV-1 clade B Tat [21]. We have demonstrated that organotypic hippocampal slice cultures (OHSCs) offer a reliable model for investigating neuroimmune interactions and for studying the mechanisms of IDO activation [22]. Here we have used this model to assess whether Tat alone or in conjunction with IFN $\gamma$ can induce IDO expression. We chose IFN $\gamma$ since this cytokine is traditionally regarded as the primary inducer of IDO [23]. IFN $\gamma$ is elevated in the brains of patients with HIVE and has been hypothesized to play a role in the pathophysiology of HAD [24]. IFN $\gamma$ synergizes with Tat to enhance chemokine expression, which in turn can amplify the inflammatory responses within the CNS of patients with AIDS-related neurological disorders [25]. However, IFN $\gamma$-independent activation pathway has also been reported in response to LPS in primary microglia and murine slices $[22,26]$. Additionally, the IFN $\gamma$-independent up-regulation of IDO expression was recently demonstrated in HIV-infected human macrophages [27]. It is unknown whether this property of IDO induction extends to OHSCs exposed to HIV proteins such as Tat. Furthermore, the precise mechanisms responsible for IFN $\gamma$-independent induction of IDO following exposure to Tat are not clearly understood.

Activation of IDO is not the sole mechanism that could be responsible for inflammation-associated depression. By reuptake of serotonin (5-HT) with high affinity in presynaptic neurons, the sodium-dependent serotonin transporter (SERT) contributes to the regulation of 5-HT neurotransmission [28]. Several cytokines, including IFN $\alpha$, IFN $\gamma$, IL- $1 \beta$ and TNF $\alpha$, are able to increase expression of SERT $[29,30]$. Additionally, a recent study reported that HIV-1 clade B and C Tat differentially induce SERT expression in dendritic cells [31]. For this reason, we included SERT in the possible targets of HIV-1 Tat in the in vitro model of OHSCs.

HIV-1 Tat mediates its biological functions by activating a variety of signaling pathways and transcription factors. The p38 mitogen-activated protein kinase (MAPK) is activated by Tat in a variety of cell types, including monocytes [32,33], macrophages [34], astrocytes [35] and the THP-1 cell line [36]. Since p38 MAPK is required for IDO expression in THP-1 cells [37], we investigated whether this signaling pathway also mediates Tat-induced expression of IDO in OHSCs. In the present study, we show that Tat induces the expression of IDO and synergizes with exogenous IFN $\gamma$ to increase IDO induction in OHSCs and the effect of Tat is mediated by p38 MAPK activation.

\section{Methods \\ Reagents}

Recombinant Tat 1-72 was provided by Professor Avindra Nath through a contract with the University of Kentucky. Stock solutions of Tat 1-72 were prepared in phosphate buffered saline (PBS) $(1 \mathrm{ug} / \mathrm{ul})$ and stored at 
$-80^{\circ} \mathrm{C}$ until use. Recombinant murine IFN $\gamma$ (cat\# 315-05) was from PeproTech, Inc. Heat-inactivated horse serum (cat\# SH30074.03), Hank's balanced salt solution (HBSS, cat\# SH30030.03) and minimal essential media (MEM) (cat\# SH30024.02) were all from Hyclone. Gey's balanced salt solution (GBSS, cat\# G9779) was from Sigma, D-glucose (cat\# 15023-021) was from GibcoBRL and the kits for enzyme-linked immunosorbent assays (ELISA) were obtained from R\&D Systems (Wiesbaden, DE). TRIzol reagent was purchased from Invitrogen Life Technologies (Carlsbad, CA). Reagents for RT-PCR were all from Applied Biosystems as follows: high capacity cDNA reverse transcription kit (cat\# 4374967); RTPCR primers for IDO (cat\# Mm00492586_m1), TNFa (cat\# Mm00443258_m1), IL-6 (cat\# Mm00446190_m1), the inducible isoform of nitric oxide synthase (iNOS) (cat\# Mm00440485_m1) and glyceraldehyde-3-phosphate dehydrogenase (GAPDH; cat\# Mm999999_g1). Antibodies specific for p38 (cat\# 9212) and phosphorylated p38 (p- p38, cat\# 9211) were purchased from Cell Signaling Biotechnology (Danvers, MA), whereas the secondary horseradish peroxidase (HRP)-linked rabbit anti-mouse antibody (NA934V) was obtained from GE Healthcare Biosciences (Piscataway, NJ). The p38 MAPK inhibitor SB 202190 (cat\# 559397) was from EMD Chemicals, Inc. (USA). Protein was measured with a standard Bradford assay kit (cat\# 500-0113, 0114, 0115) and Immun-Blot polyvinylidene difluoride (PVDF, cat\# 1620177) membranes were from Bio-RAD (Hercules, CA). ECL Western blotting detection reagents (cat\# RPN2106V1, RPN2106V2) were obtained from GE Healthcare Little Chalfont (Bucks, UK).

\section{Mice}

All animal care and use procedures were conducted in accordance with the Guide for the Care and Use of Laboratory Animals (National Research Council) and approved by the Institutional Animal Care and Use Committee. Experiments conducted in vivo were performed on 12-week-old male C57BL/6J mice obtained from a colony raised in our laboratory. Mice were individually housed in standard shoebox cages, with wood shavings as litter, in a temperature- $\left(23^{\circ} \mathrm{C}\right)$ and humidity- (45-55\%) controlled environment with a $12 / 12 \mathrm{~h}$ modified dark-light cycle (lights on 10:00 P.M.-10:00 A. M.). Food and water were available ad libitum.

\section{Intracerebroventricular (i.c.v.) Cannulation}

Mice were surgically implanted with a single guide cannula (Plastics One, Roanoke, VA) directed toward the lateral ventricle, As previously described [10]. The guide cannulas were kept clean and covered using a screw on cannula dummy for mice (Plastics One, Roanoke, VA). Coordinates for placement of the guide cannula were
$1.5 \mathrm{~mm}$ lateral, $0.6 \mathrm{~mm}$ posterior, and $1.3 \mathrm{~mm}$ dorsal with respect to bregma. These coordinates placed the guide cannula $1 \mathrm{~mm}$ dorsal to the lateral ventricle. Mice were allowed to recover 2 weeks before treatment and initiation of behavioral tests. After recovery, mice were slowly injected over 1 min i.c.v. with phosphate buffered saline (PBS) or Tat (40 ng) in a volume of $1 \mu \mathrm{l}$. This dose of Tat was selected on its ability to reliably induce IDO expression in human astrocytes [38].

\section{Forced swim test (FST)}

The forced swim test was conducted at $24 \mathrm{~h}$ post i.c.v. injection of Tat for a five-min period and the mice were video recorded for future analysis. Immobility was defined as passive floating behavior or any movement necessary for the mouse to keep its head above water, as described previously [10].

\section{Organotypic hippocampal slice cultures}

Murine hippocampal slice cultures were prepared using the static interface culture method [22]. Briefly, 6- to 8day-old C57BL/6J mice were decapitated. The brains and meninges were removed, followed by separation of the hippocampus from both hemispheres. Hippocampi were dissected and transverse slices $(350 \mu \mathrm{m}$ in thickness) were prepared using a McIlwain tissue chopper (Campden Instruments Ltd, UK). Slices were placed for $1 \mathrm{~h}$ at $4^{\circ} \mathrm{C}$ into GBSS supplemented with $2 \mathrm{mg} / \mathrm{ml}$ D-glucose and were then transferred onto porous $(0.4$ $\mu \mathrm{m})$ transparent membrane inserts $(30-\mathrm{mm}$ in diameter; Millipore) with five slices on each insert. Inserts were then placed into six-well culture plates. Each well contained $1.2 \mathrm{ml}$ of nutrient medium composed of $25 \%$ heat-inactivated horse serum, 25\% HBSS and 50\% MEM supplemented with $25 \mathrm{mM}$ D-glucose. Neither antibiotics nor anti-mycotics were used. Plates were maintained in a humidified $\mathrm{CO}_{2}$ incubator $\left(5 \% \mathrm{CO}_{2}, 95 \%\right.$ atmospheric air) at $37^{\circ} \mathrm{C}$. Medium was changed every 2-3 days. The MEM medium was changed so that it contained only $5 \%$ horse serum and $25 \mathrm{mM}$ D-glucose on the day that Tat or control medium was added. At various times following addition of Tat, supernatants were collected and stored at $-80^{\circ} \mathrm{C}$ for measurement of cytokines. Slices were washed 3 times with cold PBS and stored at $-80^{\circ} \mathrm{C}$ for isolation of total cellular RNA and for western blotting. Slice viability was evaluated using both propidium iodide (PI) staining and the amount of lactate dehydrogenase (LDH) released into the culture medium by CytoTox ${ }^{96}$ non-radioactive cytotoxicity kit.

\section{Reverse transcription and real-time RT-PCR}

Total cellular RNA from the hippocampus and cultured slices was extracted in TRIzol reagent, as previously described [22]. Total mRNA (1-2 $\mu \mathrm{g})$ was reverse 
transcribed to cDNA using the high capacity cDNA reverse transcription kit from Ambion. Samples were analyzed in duplicate. Data were analyzed using the comparative threshold cycle method, as described elsewhere (Applied Biosystems user bulletin no.2).

\section{Enzyme-linked immunosorbent assays (ELISAs)}

TNF $\alpha$ and IL-6 were measured in OHSCs supernatants with validated specific ELISA assays [22]. Briefly, $100 \mu \mathrm{l}$ of each sample were added in duplicate to ELISA plates pre-coated with an anti-TNF $\alpha$ or IL- 6 capture antibody. Recombinant murine TNF $\alpha$ and IL- 6 standards ranged from 0 to $1,000 \mathrm{pg} / \mathrm{ml}$. The lower assay limit of detection was $16 \mathrm{pg} / \mathrm{ml}$. Absorbance was measured on an OPTImax ELISA plate reader. TNF $\alpha$ and IL-6 concentrations are expressed as picograms per milliliter.

\section{Western blot analysis}

Western blotting experiments were conducted as previously described [26], with minor modifications. Briefly, slices were lysed in cold lysis buffer. Equal amounts of protein $(40 \mu \mathrm{g})$ were separated on $10 \%$ polyacrylamide gels. Proteins were then transferred from the gel to PVDF membranes using a Bio-Rad Laboratories Mini Protein 3 system. After treating PVDF membranes with blocking buffer (TBS/0.1\% Tween20 (TBST) containing $2 \% \mathrm{BSA}$ ) for $1 \mathrm{~h}$ at room temperature, they were incubated overnight at $4 \mathrm{C}$ with blocking buffer containing primary antibodies specific for phosphorylated p38 or p38, (1:1000 dilution). Membranes were washed extensively with TBST and then incubated for $1 \mathrm{~h}$ at room temperature with a secondary antibody coupled to horseradish peroxidase (HRP)-conjugated sheep antimouse IgG antibodies at a dilution of 1:2000 in blocking buffer. Finally, membranes were washed extensively with TBST and developed with an enhanced chemiluminescence ECL Western Blot Detection Reagent. Blots were covered with transparency film and then inserted into a Fujifilm LAS-4000 System Configured for multifunctional analysis (Fujifilm, Life Science, Stamford, USA). Densitometric analysis of autoradiograms was performed using publically available IMAGE-J software from the National Institutes of Health (Bethesda, MD). Densitometric summaries were expressed as ratios of phosphorylated p38 to total p38.

\section{Statistical analysis}

Data were analyzed using a one-way (treatment) or two-way (pretreatment $x$ treatment) ANOVA, followed by a post hoc pairwise multiple comparison using Fischer's LSD test if the interaction was significant. All data are presented as means \pm SEM. Differences were considered significant if the probability reached a level of 0.05 or less.

\section{Results}

Tat induces depressive-like behavior in C57BL/6J mice in the absence of sickness

Mice were treated with i.c.v. PBS or Tat (40ng). At $24 \mathrm{~h}$ post Tat, sickness and depressive-like behavior were assessed by body weight loss and FST, respectively. Consistent with our previous findings [10], the $24 \mathrm{~h}$ changes in body weight did not differ according to treatment (Figure 1A, p >0.05). Tat-treated mice displayed increased immobility in the FST at $24 \mathrm{~h}$ post-treatment compared to control mice (Figure 1B, p < 0.05).

HIV-1 Tat induces biochemical markers of inflammationassociated depression in murine OHSCs

We recently found that central injection of HIV-1 Tat (40 ng) increased brain IDO and cytokine steady-state transcripts at $4 \mathrm{~h}[10]$. Here we determined whether the expression of IDO and cytokines response to Tat occurs in murine OHSCs as it does in the CNS in vivo. Based on the in vivo response to central injection of Tat [10], the time point of $6 \mathrm{~h}$ was selected for carrying out doseresponse experiments to determine the effect of Tat on cytokine and IDO expression. Slices were exposed to 4, 40 and $400 \mathrm{ng} / \mathrm{slice}$ of Tat on day 10 in culture. As shown in Figure 2, Tat significantly increased TNF $\alpha$, IL6 and iNOS at the mRNA level $(p<0.05)$ in a dosedependent manner, with a maximum at $400 \mathrm{ng} / \mathrm{slice}$. Tat-induced increases in TNF $\alpha$ and IL- 6 mRNA expression were paralleled by a concomitant increase in protein production (Figure 2, $p<0.05$ ). Increased iNOS mRNA was not associated with any detectable increase in nitrite levels at the $6 \mathrm{~h}$ time point (data not shown). Induction of SERT mRNA reached a maximum at $4 \mathrm{ng} /$ slice (Figure $2, p<0.05$ ).
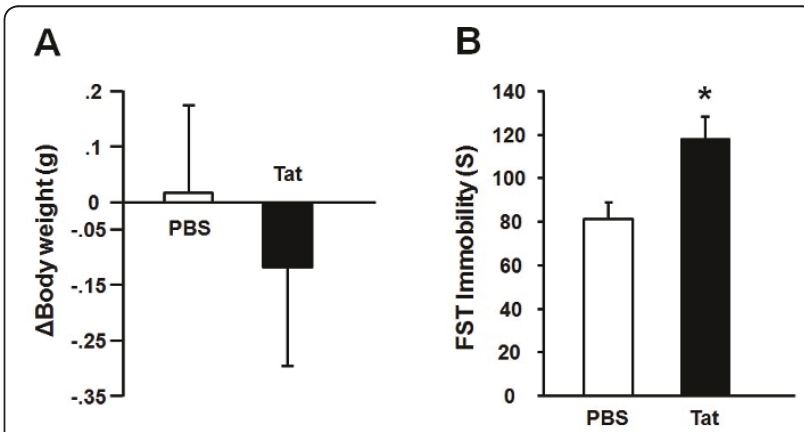

Figure 1 LPS administered via the i.c.v. route induces depressive-like behavior. Mice were injected i.c.v. with either PBS or Tat (40 ng). (A) Body weight was measured before and $24 \mathrm{~h}$ after injection and expressed as body weigh change. (B) Duration of immobility was quantified during a 5 min forced swim test that took place $24 \mathrm{~h}$ following administration of Tat or PBS. Data represent mean \pm SEM ( $n=6$ mice/group). ${ }^{*} p<0.05$ compared to PBS. 

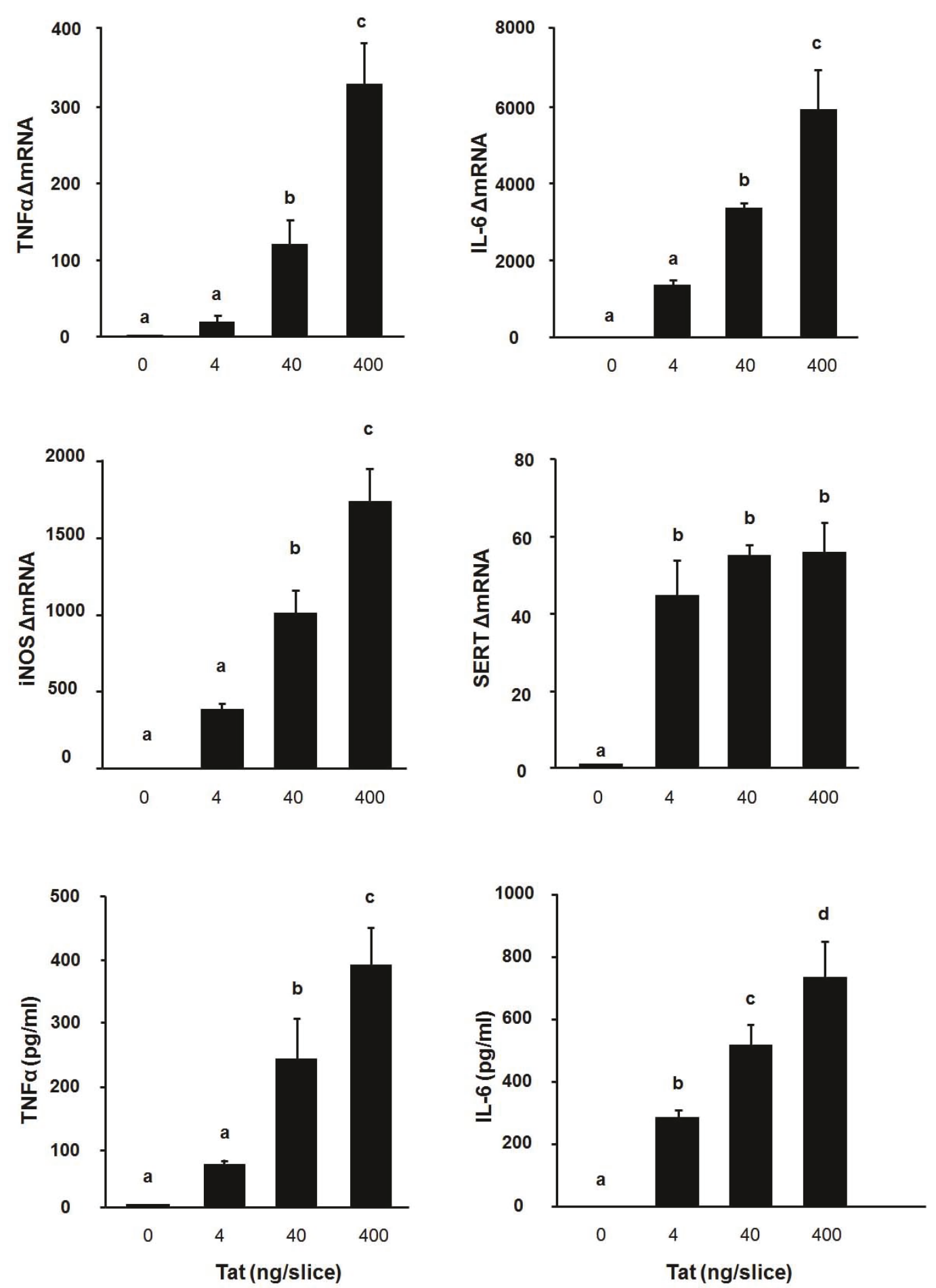

Figure 2 Tat induces TNF $\alpha$, IL-6, iNOS and SERT expression in OHSCs in a dose-dependent manner. Tat at a dose of 4, 40 and 400 ng/ slice was added to the medium after 10 days in culture. Tissue and media were collected $6 \mathrm{~h}$ later. Average Ct values for $4,40 \mathrm{and} 400 \mathrm{ng} / \mathrm{slice}$ Tat were, respectively, for TNF $\alpha: 22.54 \pm 0.68,19.85 \pm 0.43,18.53 \pm 0.43 ;$ IL-6: $21.34 \pm 0.21,19.88 \pm 0.03,19.29 \pm 0.12$; iNOS: $21.69 \pm 0.14,19.92 \pm$ $0.14,19.42 \pm 0.26$; SERT: $28.45 \pm 0.04,27.91 \pm 0.02,28.09 \pm 0.15$. Levels of TNF $\alpha$ and IL-6 (pg/ml) were measured in the supernatant by ELISA. Data represent the mean \pm SEM ( $n=3$ in each group). Bars labeled with different letters $(a, b, c$ or $d)$ are significantly different from each other at $p<0.05$. 
For kinetic studies, OHSCs were exposed to $40 \mathrm{ng} /$ slice Tat for 2, 6 and $12 \mathrm{~h}$ on day 10 of culture. As shown in Figure 3, the greatest expression of both mRNA and protein for TNF $\alpha$ occurred at $2 \mathrm{~h}(p<0.05)$ and $6 \mathrm{~h}(p<0.05)$, respectively. IL- 6 mRNA peaked at 6 $\mathrm{h}(p<0.05)$ and gradually decreased at $12 \mathrm{~h}$. IL- 6 concentration in the culture medium increased after $6 \mathrm{~h}(p$ $<0.05)$ and reached a maximum at $12 \mathrm{~h}(p<0.05)$. iNOS and SERT mRNA increased at $6 \mathrm{~h}(p<0.05)$ and peaked at $12 \mathrm{~h}(p<0.05)$, but there was no concomitant increase in nitrite levels at any time point (data not shown). We also used real-time RT-PCR to determine whether Tat induces IDO steady-state transcripts in OHSCs as it does in vivo. To determine an optimal dose for Tat-induced expression of IDO, OHSCs were treated with 4, 40 and $400 \mathrm{ng} /$ slice of Tat for $6 \mathrm{~h}$. As shown in Figure 4A, IDO mRNA expression could be detected at $4 \mathrm{ng} / \mathrm{slice}$ Tat and peaked at $40 \mathrm{ng} /$ slice Tat $(p<0.05)$. Kinetic studies were then carried out in which OHSCs were exposed to Tat (40 ng/slice) for 2, 6 and $12 \mathrm{~h}$. As shown in Figure 4B, IDO mRNA could not be detected in OHSCs prior to addition of Tat (40 amplification cycles). However, IDO expression was significantly induced by Tat at $6 \mathrm{~h}(p<0.05)$ with no further increase at $12 \mathrm{~h}$. This effect was similar in intensity to that of exogenous IFN $\gamma(10 \mathrm{ng} / \mathrm{ml}$, Figure $4 \mathrm{C}, \mathrm{p}<0.05)$. Moreover, pretreatment of OHSCs with the same dose of IFN $\gamma 24 \mathrm{~h}$ before Tat markedly amplified IDO responses to Tat (Figure $4 \mathrm{C}, \mathrm{p}<0.01$ ). However, the Tat-induced expression of IDO did not require endogenous synthesis of IFN $\gamma$ because no IFN $\gamma$ mRNA could be detected at $6 \mathrm{~h}$ in Tat-stimulated slices (40 amplification cycles, data not shown).

\section{p38 MAPK is required for HIV-1 Tat-induced IDO expression}

In accordance with the results of others on the effects of Tat on p38 MAPK in various cell types [32-36], we confirmed that HIV-1 Tat can activate p38 MAPK in OHSCs. Slices were treated with Tat for 15, 30, 60 and $120 \mathrm{~min}$ respectively and the lysates were analyzed for phospho-p38 activity by Western blot analysis. We found that Tat induced significant phosphorylation of p38 MAPK as early as 15 min (Figure 5A, p < 0.05) with a maximum at 60 min (Figure 5A, $\mathrm{p}<0.05$ ).

To determine whether p38 MAPK is involved in Tatinduced IDO expression, the p38 MAPK inhibitor SB 202190 was employed. We previously established that $30 \mu \mathrm{M}$ SB 202190 significantly suppresses cytokine expression at both the mRNA and protein levels in response to LPS stimulation (data not shown). The dose of $30 \mathrm{uM}$ was therefore selected for further experiments on Tat-induced IDO expression. Slices were pretreated with SB $202190(30 \mu \mathrm{M})$ for $30 \mathrm{~min}$ before stimulation with Tat for another 6 h. SB 202190 abrogated the Tatinduced expression of IDO, IL-6, iNOS and SERT transcripts, although this effect was only partial for TNFa mRNA (Figure 5B, p < 0.01). SB 202190 also fully blocked the Tat-induced release of cytokine proteins in the slice supernatants (Figure 5B, p < 0.01). Importantly, neither Tat nor SB 202190 affected viability of the cells, as determined by measuring both PI staining and release of lactate dehydrogenase into the culture medium (data not shown). These data clearly demonstrate that the p38 MAPK signaling pathway is necessary for the Tatinduced expression of both proinflammatory cytokines and IDO.

\section{Discussion}

Results of the present experiments establish that HIV-1 Tat induces depressive-like behavior in vivo and induces production of proinflammatory cytokine in vitro in murine OHSCs and increases expression of IDO and SERT. These changes are dependent on activation of the p38 MAPK signaling pathway.

Our in vivo data show that Tat increases the duration of immobility in the forced swim test in mice without inducing any sickness, as measured by the lack of body weight loss. These data are in agreement with already published findings from our group on depressogenic activity of Tat [10]. The mechanisms of the depressogenic activity of Tat were further investigated in vitro. Compared to primary cultures of brain cells, OHSCs have the advantage of preserving the cellular and connective organization as well as several fundamental in vivo-like characteristics such as glial-neuronal interactions $[39,40]$. Although this preparation has previously been used for studying the detrimental effects of proinflammatory cytokines on long-term potentiation in the rat system $[41,42]$, OHSCs have rarely been used for the investigation of neuroimmune interactions. Our previous experiments demonstrated that long term culture of OHSCs can be reliably used to study neuroimmune mechanisms of induction of IDO [22]. We therefore employed OHSCs in the present experiments to study the mechanisms involved in the expression of IDO by Tat.

Depression is an important comorbid condition of HIV infection. We previously demonstrated that IDO, the first and rate-limiting enzyme in the synthesis of KYN from the precursor of Trp, is both sufficient and necessary to mediate depressive-like behavior in response to either acute or chronic activation of the immune system in mice $[43,44]$. Moreover, the increase in brain IDO activity is invariably preceded by enhanced expression of IDO mRNA, which can therefore be used as a surrogate marker of IDO activation $[26,43,44]$. Therefore, in the present study, we examined the effects 

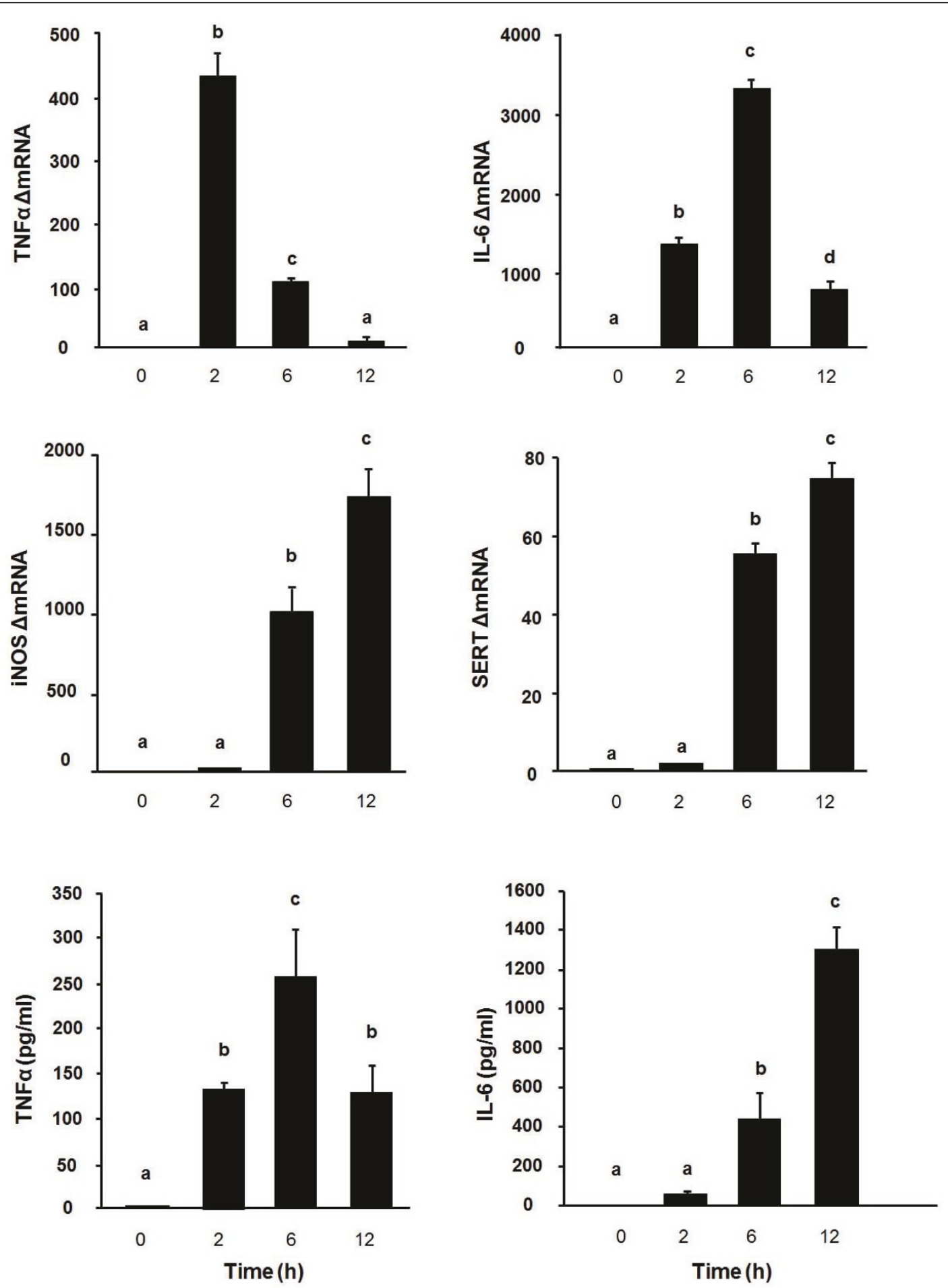

Figure 3 Tat induces TNF $\alpha$, IL-6, iNOS and SERT expression in OHSCs in a time-dependent manner. Hippocampal slices were treated with Tat (40 ng/slice) and tissue and media were collected at various times. Average Ct values at 2,6 and $12 \mathrm{~h}$ were, respectively, for TNF $\alpha$ : $18.24 \pm$ $0.76,20.42 \pm 0.75,23.32 \pm 1.01$; IL-6: $21.08 \pm 0.19,19.88 \pm 0.03,21.98 \pm 0.31$; iNOS: $28.47 \pm 1.91,19.92 \pm 0.14,19.08 \pm 0.25 ;$ SERT: 32.42 \pm 0.28 $27.91 \pm 0.02,27.50 \pm 0.18$. Levels of TNF $\alpha$ and $I L-6(\mathrm{pg} / \mathrm{ml})$ were measured in the supernatant by ELISA. Data represent the mean \pm SEM $(n=3$ in each group). Bars labeled with different letters ( $a, b, c$ or d) are significantly different from each other at $p<0.05$. 


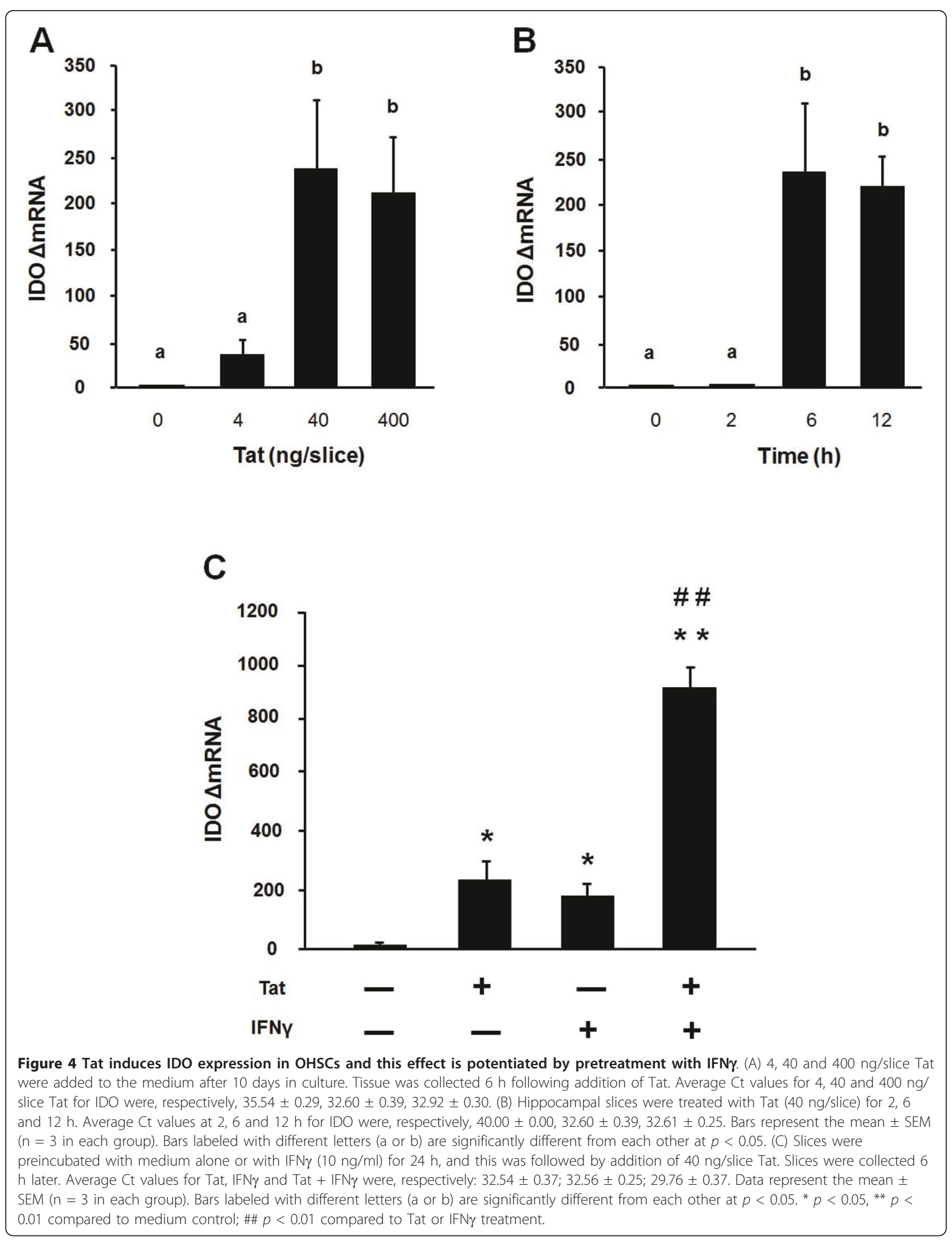




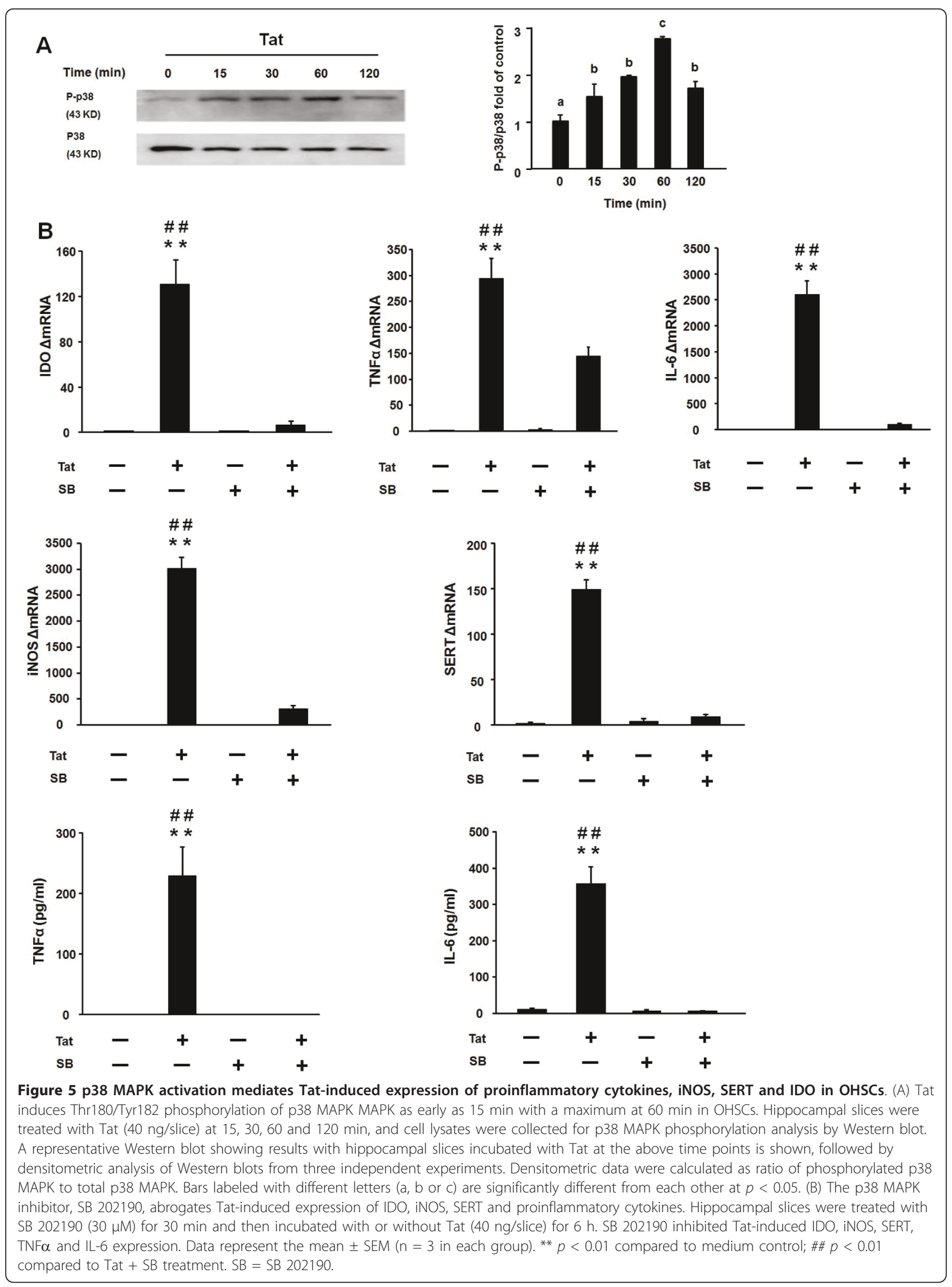


of Tat on IDO mRNA in OHSCs. As shown in Figure 2, HIV-1 Tat protein significantly up-regulates IDO mRNA expression in OHSCs. These results are consistent with previous studies that describe Tat-mediated induction of the IDO expression in other types of cells [19-21]. These in vitro data are also in accordance with our in vivo results showing that Tat induced depressivelike behavior is associated with increased expression of IDO in the brain [10]. Taken together, these data provide the first evidence to indicate that activation of IDO in response to Tat stimulation in the brain could be a key event in the switch from sickness to depressive-like behavior.

IFN $\gamma$ is considered to be the prototypical inducer of IDO in a variety of cells [23] as well as in clinical situations in which inflammation-associated depression occurs [45]. Additionally, IFN $\gamma$ is increased in the brain during HIV infection [24] and synergizes with Tat to play a critical role in the pathogenesis of HAD [25]. It is well documented that monocytes/macrophages/microglia can produce IFN $\gamma$ [46-48]. However, IDO expression appears to be up-regulated in an IFN $\gamma$-independent manner in HIV-infected human macrophages [27]. IFN $\gamma$ protein remained undetectable in HIV-infected human macrophage supernatants while IDO expression increased [27]. Our data indicate that IDO induction by Tat does not necessarily require synthesis of IFN $\gamma$ because no IFN $\gamma$ transcripts could be detected at $6 \mathrm{~h}$. These observations are in accordance with the results obtained by Boasso et al. [49]. Boasso et al. reported that blockade of either type I or type II IFNs by antibodies was ineffective in preventing the induction of IDO in human peripheral blood mononuclear cells exposed to R5- or X4-trophic HIV. Therefore, our data extend the developing concept that IDO can be induced by Tat in an IFNy-independent mechanism.

Addition of Tat to OHSCs induced the synthesis and release of proinflammatory cytokines. These cytokines are well known to stimulate HIV-1 replication and contribute to HIV pathogenesis [50,51]. Increased expression of proinflammatory cytokines in the brain is observed in HIV-1 infected patients [52]. Tat also can up-regulate cytokine expression, such as IL-1 $\beta$ and TNF $\alpha$, in peripheral blood macrophages, CNS-derived cell lines and primary astrocytes, microglia $[53,54]$ and human monocytes [55]. The large increase in proinflammatory cytokine expression could mediate IDO induction by Tat. Both in vivo and in vitro studies have shown that IDO induction is associated to IL-1 $\beta$. For instance, pretreatment in vivo with the anti-inflammatory tetracycline derivative minocycline attenuates LPSinduced expression of brain IL- $1 \beta$, indicating that IL-1 $\beta$ probably participates in LPS-induced expression of brain IDO [44]. A synergistic activation of IDO by IL-1 $\beta$,
TNF- $\alpha$ and IL- 6 has been reported in human monocytic THP-1 cells exposed to LPS [37]. We observed that IL$1 \beta$ mRNA can be induced by Tat in OHSCs (data not shown). However, this induction does not lead to release of IL- $1 \beta$ protein if exogenous ATP is not added to the culture. This is because ATP is necessary for processing and release of the mature IL-1 $\beta$ protein [56]. In the absence of IL- $1 \beta$, the most likely mediators of IFN $\gamma$ independent IDO induction in OHSCs are TNF- $\alpha$ and IL-6. IDO induction has been shown to be mediated mainly by TNF- $\alpha$, but not by IL- 6 in human monocytic THP-1 cell cultures exposed to immune stimulation [57]. However, IL-6 can synergize with TNF- $\alpha$ to increase IDO activity [37]. The exact cytokine signaling pathways that are predominantly involved in the production of IDO in response to Tat in OHSCs remain to be elucidated.

In addition to IDO induction by Tat, we observed a robust induction of SERT mRNA in response to Tat. This finding indicates that OHSCs can serve as a reliable in vitro model for investigating the possible contribution of serotonin re-uptake mechanisms in comorbid depressive disorders in HIV-infected patients. Whether this change at the mRNA level translates into functional changes in SERT remains to be established. This is an important perspective since differences in the expression and function of SERT are well known to affect many human and mouse quantitative traits, including anxietyand depression-related behaviors [58].

To elucidate the signaling pathways that mediate Tatinduced IDO expression, we examined whether Tat contributes to overexpression of IDO by activating p38 MAPK. This signaling pathway has been shown to be required for IDO expression in THP-1 cells following LPS stimulation [37]. Moreover, HIV-1 Tat protein has been reported to activate p38 MAPK in a variety of cells, including monoctyes [32,33], macrophages [34], astrocytes [35] and the human THP-1 cell line [36]. We therefore tested the possibility that Tat-induced $\mathrm{p} 38$ promotes expression of IDO in OHSCs. SB 202190, a highly selective, potent and cell permeable inhibitor of p38 MAPK [59], was employed to inhibit p38 activation. It binds within the ATP pocket of the active kinase with a $\mathrm{K}_{\mathrm{d}}$ of $38 \mathrm{nM}$, as measured in recombinant human $\mathrm{p} 38$, and selectively inhibits both the p38 $\alpha$ and $\beta$ isoforms. We observed that SB 202190 significantly inhibited Tat-induction of IDO in OHSCs, which is consistent with the possibility that p38 may be involved in the development of Tat-induced depressive-like behavior.

The demonstration of an inhibitory effect of SB 202190 on Tat-induced changes in OHSCs does not mean p38 MAPK signaling is directly responsible for these effects. Activation of p38 MAPK could act 
indirectly via $\mathrm{NF}_{\mathrm{k}} \mathrm{B}$ activation $[60,61]$ or $\mathrm{AP}-1$ activity at both the transcriptional and post-transcriptional levels [62]. The human IDO promoter region contains multiple AP-1 and $\mathrm{NF}_{\mathrm{k}} \mathrm{B}$ sites [37]. Therefore, the possibility that other transcription factors are involved in Tatinduced IDO expression cannot be dismissed. However, our data clearly demonstrate that Tat-induced IDO expression in OHSCs is mediated, at least in part, through a p38-dependent mechanism.

In conclusion, results of the present studies demonstrate that p38 MAPK is potently involved in HIV-1 Tat-induced IDO expression. These studies provide further evidence for targeting the brain IDO and p38 MAPK signaling pathway in the treatment of depressive disorders associated with HIV infection.

\section{Acknowledgements}

This work was supported by NIH grants to KWK (R01 AG 029573 and R01 AG 029573-04S1) and RD (R01 MH 079829)

\section{Author details \\ 'Integrative Immunology and Behavior Program, Department of Animal Sciences, College of ACES, University of Illinois at Urbana-Champaign, Urbana, Illinois 61801, USA. ²Department of Pathology, College of Medicine, University of Illinois at Urbana-Champaign, Urbana, Illinois 61801-3873, USA. ${ }^{3}$ Neuroscience Program, University of Illinois at Urbana-Champaign, Urbana, Illinois 61801, USA.}

\section{Authors' contributions}

XF designed the experiments with the help of KWK and RD, performed the in vitro component of theseexperiments, analyzed the results and drafted the manuscript. MAL was responsible for performing and analyzing the in vivo component of these experiments. RD and KWK secured funding for the project and helped with the final version of the manuscript. All authors read and approved the final manuscript.

\section{Competing interests}

RD has received honorarium from Astra-Zeneca, Bristol-Myers-Squibb, Janssen and Lundbeck Laboratories. He is working as a consultant for Lundbeck Laboratories. KWK has received honorarium from Astra-Zeneca.

Received: 8 April 2011 Accepted: 2 August 2011

Published: 2 August 2011

\section{References}

1. Ciesla JA, Roberts JE: Meta-analysis of the relationship between HIV infection and risk for depressive disorders. Am J Psychiatry 2001 158:725-730

2. Evans DL, Charney DS, Lewis L, Golden RN, Gorman JM, Krishnan KR, Nemeroff CB, Bremner JD, Carney RM, Coyne JC, et al: Mood disorders in the medically ill: scientific review and recommendations. Biol Psychiatry 2005, 58:175-189.

3. Anthony IC, Ramage SN, Carnie FW, Simmonds P, Bell JE: Influence of HAART on HIV-related CNS disease and neuroinflammation. J Neuropathol Exp Neurol 2005, 64:529-536.

4. Merrill JE, Chen IS: HIV-1, macrophages, glial cells, and cytokines in AIDS nervous system disease. Faseb J 1991, 5:2391-2397.

5. Li W, Li G, Steiner J, Nath A: Role of Tat protein in HIV neuropathogenesis. Neurotox Res 2009, 16:205-220.

6. Miller RJ, Meucci O: AIDS and the brain: is there a chemokine connection? Trends Neurosci 1999, 22:471-479.

7. Singer EJ, Valdes-Sueiras M, Commins D, Levine A: Neurologic presentations of AIDS. Neurol Clin 2010, 28:253-275.

8. Barak O, Weidenfeld J, Goshen I, Ben-Hur T, Taylor AN, Yirmiya R: Intracerebral HIV-1 glycoprotein 120 produces sickness behavior and pituitary-adrenal activation in rats: role of prostaglandins. Brain Behav Immun 2002, 16:720-735.

9. Barak O, Goshen I, Ben-Hur T, Weidenfeld J, Taylor AN, Yirmiya R: Involvement of brain cytokines in the neurobehavioral disturbances induced by HIV-1 glycoprotein120. Brain Res 2002, 933:98-108.

10. Lawson MA, Kelley KW, Dantzer R: Intracerebroventricular administration of HIV-1 Tat induces brain cytokine and indoleamine 2,3-dioxygenase expression: A possible mechanism for AIDS comorbid depression. Brain Behav Immun 2011.

11. Dantzer R, O'Connor JC, Freund GG, Johnson RW, Kelley KW: From inflammation to sickness and depression: when the immune system subjugates the brain. Nat Rev Neurosci 2008, 9:46-56.

12. O'Connor JC, Andre C, Wang Y, Lawson MA, Szegedi SS, Lestage J, Castanon N, Kelley KW, Dantzer R: Interferon-gamma and tumor necrosis factor-alpha mediate the upregulation of indoleamine 2,3-dioxygenase and the induction of depressive-like behavior in mice in response to bacillus Calmette-Guerin. J Neurosci 2009, 29:4200-4209.

13. Schwarcz R, Pellicciari R: Manipulation of brain kynurenines: glial targets, neuronal effects, and clinical opportunities. J Pharmacol Exp Ther 2002, 303:1-10.

14. Fuchs D, Forsman A, Hagberg L, Larsson M, Norkrans G, Reibnegger G, Werner ER, Wachter H: Immune activation and decreased tryptophan in patients with HIV-1 infection. J Interferon Res 1990, 10:599-603.

15. Sardar AM, Reynolds GP: Frontal cortex indoleamine-2,3-dioxygenase activity is increased in HIV-1-associated dementia. Neurosci Lett 1995, 187:9-12.

16. Potula R, Poluektova L, Knipe B, Chrastil J, Heilman D, Dou H, Takikawa O, Munn DH, Gendelman HE, Persidsky Y: Inhibition of indoleamine 2,3dioxygenase (IDO) enhances elimination of virus-infected macrophages in an animal model of HIV-1 encephalitis. Blood 2005, 106:2382-2390.

17. Burudi EM, Marcondes MC, Watry DD, Zandonatti M, Taffe MA, Fox HS: Regulation of indoleamine 2,3-dioxygenase expression in simian immunodeficiency virus-infected monkey brains. J Virol 2002, 76:12233-12241.

18. Heyes MP, Ellis RJ, Ryan L, Childers ME, Grant I, Wolfson T, Archibald S, Jernigan TL: Elevated cerebrospinal fluid quinolinic acid levels are associated with region-specific cerebral volume loss in HIV infection. Brain 2001, 124:1033-1042.

19. Grant RS, Naif H, Thuruthyil SJ, Nasr N, Littlejohn T, Takikawa O, Kapoor V: Induction of indoleamine 2,3-dioxygenase in primary human macrophages by HIV-1. Redox Rep 2000, 5:105-107.

20. Smith DG, Guillemin GJ, Pemberton L, Kerr S, Nath A, Smythe GA, Brew BJ Quinolinic acid is produced by macrophages stimulated by platelet activating factor, Nef and Tat. J Neurovirol 2001, 7:56-60.

21. Wong JK, Campbell GR, Spector SA: Differential induction of interleukin-10 in monocytes by HIV-1 clade B and clade C Tat proteins. J Biol Chem 2010, 285:18319-18325

22. Fu X, Zunich SM, O'Connor JC, Kavelaars A, Dantzer R, Kelley KW: Central administration of lipopolysaccharide induces depressive-like behavior in vivo and activates brain indoleamine 2,3 dioxygenase in murine organotypic hippocampal slice cultures. J Neuroinflammation 2010, 7:43.

23. Taylor MW, Feng GS: Relationship between interferon-gamma, indoleamine 2,3-dioxygenase, and tryptophan catabolism. Faseb J 1991, 5:2516-2522.

24. Shapshak P. Duncan R, Minagar A, Rodriguez de la Vega P, Stewart RV, Goodkin K: Elevated expression of IFN-gamma in the HIV-1 infected brain. Front Biosci 2004, 9:1073-1081.

25. Dhillon N, Zhu X, Peng F, Yao H, Williams R, Qiu J, Callen S, Ladner AO, Buch S: Molecular mechanism(s) involved in the synergistic induction of CXCL10 by human immunodeficiency virus type 1 Tat and interferongamma in macrophages. J Neurovirol 2008, 14:196-204.

26. Wang Y, Lawson MA, Dantzer R, Kelley KW: LPS-induced indoleamine 2,3dioxygenase is regulated in an interferon-gamma-independent manner by a JNK signaling pathway in primary murine microglia. Brain Behav Immun 2010, 24:201-209.

27. Maneglier B, Malleret B, Guillemin GJ, Spreux-Varoquaux O, Devillier $P$, Rogez-Kreuz C, Porcheray F, Therond P, Dormont D, Clayette P: Modulation of indoleamine-2,3-dioxygenase expression and activity by HIV-1 in human macrophages. Fundam Clin Pharmacol 2009, 23:573-581 
28. Blakely RD, Berson HE, Fremeau RT Jr, Caron MG, Peek MM, Prince HK, Bradley CC: Cloning and expression of a functional serotonin transporter from rat brain. Nature 1991, 354:66-70.

29. Morikawa O, Sakai N, Obara H, Saito N: Effects of interferon-alpha, interferon-gamma and CAMP on the transcriptional regulation of the serotonin transporter. Eur J Pharmacol 1998, 349:317-324.

30. Zhu CB, Blakely RD, Hewlett WA: The proinflammatory cytokines interleukin-1beta and tumor necrosis factor-alpha activate serotonin transporters. Neuropsychopharmacology 2006, 31:2121-2131.

31. Samikkannu T, Rao KV, Gandhi N, Saxena SK, Nair MP: Human immunodeficiency virus type 1 clade $B$ and $C$ Tat differentially induce indoleamine 2,3-dioxygenase and serotonin in immature dendritic cells: Implications for neuroAIDS. J Neurovirol 2010, 16:255-263.

32. Gee K, Angel JB, Mishra S, Blahoianu MA, Kumar A: IL-10 regulation by HIVTat in primary human monocytic cells: involvement of calmodulin/ calmodulin-dependent protein kinase-activated p38 MAPK and Sp-1 and CREB-1 transcription factors. J Immunol 2007, 178:798-807.

33. Leghmari K, Bennasser $Y$, Tkaczuk J, Bahraoui E: HIV-1 Tat protein induces IL-10 production by an alternative TNF-alpha-independent pathway in monocytes: role of PKC-delta and p38 MAP kinase. Cell Immunol 2008, 253:45-53

34. Leghmari K, Contreras X, Moureau C, Bahraoui E: HIV-1 Tat protein induces TNF-alpha and IL-10 production by human macrophages: differential implication of PKC-betall and -delta isozymes and MAP kinases ERK1/2 and p38. Cell Immunol 2008, 254:46-55.

35. Ju SM, Song HY, Lee JA, Lee SJ, Choi SY, Park J: Extracellular HIV-1 Tat upregulates expression of matrix metalloproteinase- 9 via a MAPK-NFkappaB dependent pathway in human astrocytes. Exp Mol Med 2009, 41:86-93.

36. Li JC, Lau AS: A role for mitogen-activated protein kinase and Ets-1 in the induction of interleukin-10 transcription by human immunodeficiency virus-1 Tat. Immunology 2007, 121:337-348.

37. Fujigaki H, Saito K, Fujigaki S, Takemura M, Sudo K, Ishiguro H, Seishima M: The signal transducer and activator of transcription 1alpha and interferon regulatory factor 1 are not essential for the induction of indoleamine 2,3-dioxygenase by lipopolysaccharide: involvement of p38 mitogen-activated protein kinase and nuclear factor-kappaB pathways, and synergistic effect of several proinflammatory cytokines. J Biochem 2006, 139:655-662

38. Samikkannu T, Saiyed ZM, Rao KV, Babu DK, Rodriguez JW, Papuashvili MN, Nair MP: Differential regulation of indoleamine-2,3-dioxygenase (IDO) by HIV type 1 clade B and C Tat protein. AIDS Res Hum Retroviruses 2009, 25:329-335.

39. Holopainen IE: Organotypic hippocampal slice cultures: a model system to study basic cellular and molecular mechanisms of neuronal cell death, neuroprotection, and synaptic plasticity. Neurochem Res 2005, 30:1521-1528.

40. Noraberg J, Poulsen FR, Blaabjerg M, Kristensen BW, Bonde C, Montero M, Meyer M, Gramsbergen JB, Zimmer J: Organotypic hippocampal slice cultures for studies of brain damage, neuroprotection and neurorepair. Curr Drug Targets CNS Neurol Disord 2005, 4:435-452.

41. Butler MP, O'Connor JJ, Moynagh PN: Dissection of tumor-necrosis factoralpha inhibition of long-term potentiation (LTP) reveals a p38 mitogenactivated protein kinase-dependent mechanism which maps to earlybut not late-phase LTP. Neuroscience 2004, 124:319-326.

42. Lonergan PE, Martin DS, Horrobin DF, Lynch MA: Neuroprotective actions of eicosapentaenoic acid on lipopolysaccharide-induced dysfunction in rat hippocampus. J Neurochem 2004, 91:20-29.

43. O'Connor JC, Lawson MA, Andre C, Briley EM, Szegedi SS, Lestage J, Castanon N, Herkenham M, Dantzer R, Kelley KW: Induction of IDO by bacille Calmette-Guerin is responsible for development of murine depressive-like behavior. J Immunol 2009, 182:3202-3212.

44. O'Connor JC, Lawson MA, Andre C, Moreau M, Lestage J, Castanon N, Kelley KW, Dantzer R: Lipopolysaccharide-induced depressive-like behavior is mediated by indoleamine 2,3-dioxygenase activation in mice. Mol Psychiatry 2009, 14:511-522

45. Widner B, Leblhuber F, Fuchs D: Increased neopterin production and tryptophan degradation in advanced Parkinson's disease. J Neural Transm 2002, 109:181-189.

46. Benveniste EN: Cytokine actions in the central nervous system. Cytokine Growth Factor Rev 1998, 9:259-275.
47. Gessani S, Belardelli F: IFN-gamma expression in macrophages and its possible biological significance. Cytokine Growth Factor Rev 1998, 9:117-123

48. Wang $X$, Suzuki $Y$ : Microglia produce IFN-gamma independently from $T$ cells during acute toxoplasmosis in the brain. J Interferon Cytokine Res 2007, 27:599-605

49. Boasso A, Herbeuval JP, Hardy AW, Anderson SA, Dolan MJ, Fuchs D, Shearer GM: HIV inhibits CD4+ T-cell proliferation by inducing indoleamine 2,3-dioxygenase in plasmacytoid dendritic cells. Blood 2007, 109:3351-3359.

50. Brabers NA, Nottet HS: Role of the pro-inflammatory cytokines TNF-alpha and IL-1beta in HIV-associated dementia. Eur J Clin Invest 2006, 36:447-458.

51. Herbein G, Gras G, Khan KA, Abbas W: Macrophage signaling in HIV-1 infection. Retrovirology 2010, 7:34

52. Xing HQ, Moritoyo T, Mori K, Sugimoto C, Ono F, Izumo S: Expression of proinflammatory cytokines and its relationship with virus infection in the brain of macaques inoculated with macrophage-tropic simian immunodeficiency virus. Neuropathology 2009, 29:13-19.

53. Minghetti L, Visentin S, Patrizio M, Franchini L, Ajmone-Cat MA, Levi G: Multiple actions of the human immunodeficiency virus type-1 Tat protein on microglial cell functions. Neurochem Res 2004, 29:965-978.

54. Nicolini A, Ajmone-Cat MA, Bernardo A, Levi G, Minghetti L: Human immunodeficiency virus type-1 Tat protein induces nuclear factor (NF)kappaB activation and oxidative stress in microglial cultures by independent mechanisms. J Neurochem 2001, 79:713-716.

55. Gandhi N, Saiyed Z, Thangavel S, Rodriguez J, Rao KV, Nair MP: Differentia effects of HIV type 1 clade $B$ and clade $C$ Tat protein on expression of proinflammatory and antiinflammatory cytokines by primary monocytes. AIDS Res Hum Retroviruses 2009, 25:691-699.

56. Mingam R, De Smedt V, Amedee T, Bluthe RM, Kelley KW, Dantzer R, Laye S: In vitro and in vivo evidence for a role of the P2X7 receptor in the release of IL-1 beta in the murine brain. Brain Behav Immun 2008, 22:234-244.

57. Fujigaki S, Saito K, Sekikawa K, Tone S, Takikawa O, Fujii H, Wada H, Noma A, Seishima M: Lipopolysaccharide induction of indoleamine 2,3dioxygenase is mediated dominantly by an IFN-gamma-independent mechanism. Eur J Immunol 2001, 31:2313-2318.

58. Murphy DL, Uhl GR, Holmes A, Ren-Patterson R, Hall FS, Sora I, DeteraWadleigh S, Lesch KP: Experimental gene interaction studies with SERT mutant mice as models for human polygenic and epistatic traits and disorders. Genes Brain Behav 2003, 2:350-364.

59. Manthey CL, Wang SW, Kinney SD, Yao Z: SB202190, a selective inhibitor of p38 mitogen-activated protein kinase, is a powerful regulator of LPSinduced mRNAs in monocytes. J Leukoc Biol 1998, 64:409-417.

60. Kan H, Xie Z, Finkel MS: HIV gp120 enhances NO production by cardiac myocytes through p38 MAP kinase-mediated NF-kappaB activation. Am J Physiol Heart Circ Physiol 2000, 279:H3138-3143.

61. Liu K, Chi DS, Li C, Hall HK, Milhorn DM, Krishnaswamy G: HIV-1 Tat protein-induced VCAM-1 expression in human pulmonary artery endothelial cells and its signaling. Am J Physiol Lung Cell Mol Physiol 2005, 289:L252-260.

62. Karin M: The regulation of AP-1 activity by mitogen-activated protein kinases. J Biol Chem 1995, 270:16483-16486.

doi:10.1186/1742-2094-8-88

Cite this article as: Fu et al: HIV-1 Tat activates indoleamine 2,3 dioxygenase in murine organotypic hippocampal slice cultures in a p38 mitogen-activated protein kinase-dependent manner. Journal of Neuroinflammation 2011 8:88. 